\title{
Maximizing Strategic Performance Results: Adopting Balanced Scorecards and BI Tools
}

\author{
Mohamed Amal el deen Ahmed, PhD \\ Faculty of engineering Computers \\ engineering and systems department \\ El-Zagazig University, Cairo, Egypt
}

\author{
Marwa Mohamed Solayman \\ Faculty of computers and information \\ systems department \\ Helwan University, Cairo, Egypt
}

\begin{abstract}
Identifying business goals, speed of business changes and ongoing changed performance figures are the key issues that organizations face when evaluating their business. Business drivers and indicators should be selectively defined and adopted, for the balanced scorecard has been prompted as a framework for managing the organization's performance. The challenge is how to define an integrated measurement framework that effectively identifies the performance strategic measures and links them to the organizations strategies and goals, and hence, to present the performance output in an effective manner that enables strategic management to apply corrective actions and initiatives towards improving the performance.
\end{abstract}

\section{General Terms}

Business Intelligence, Balanced Scorecard, strategic performance management, Strategic performance, measurement perspectives.

\section{Keywords}

BI, Strategic Performance, BSC, performance measurement, SPM.

\section{INTRODUCTION}

"How can one best measure the strategic performance by defining the most indicative performance indicators and translating strategies into action, applying the business intelligence most proper tools in the performance measurement process?"

All leading organizations seek new, smarter ways to improve performance, increase revenue, develop stronger customer relationships and increase the efficiency of workforce. [12] Business intelligence (BI) is a key factor in achieving such results as it supports informed decision making on all levels, and enables managers, executives and knowledge workers to take the most effective action in certain situations. BI tools connect people with information when and where they need it, and allow the top management to define proper strategies as well as link them to the right performance measurement frameworks.

It has become essential to use the BI approaches and tools in the performance measurement as they extract, integrate and report performance measurements metrics in organization. Hence, they let the decision makers adopt new corrective actions, new management initiatives and new future strategies. Performance management and dashboard is considered a major BI approach, and this paper focuses on adopting the Balanced Scorecard (BSC) as an applied tool of performance management and measurement and the most effective data representations, which is done by aligning the applied BSC model with the BI dashboards.

\section{PEROFMANCE MEASUREMENT BACKGROUND}

Performance measurement gives a well-defined image of organization's progress in reaching its goals. Additionally, it offers a learning culture that makes all staff members involved in decision-making based on data, and helps in finding opportunities to better develop the organization's activities and operations. Eventually, it accelerates progress in the organization and achieving its targets. [13]

To apply an efficient performance measurement framework, the paper adopted the BSC framework to achieve the balance in measuring the organization's performance. This is achieved by focusing on all business perspectives - rather than measuring the financial performance only - as well as focusing on representing the results with the BI tools.

Business Intelligence is one of the core components used in the enterprise Performance Management. BI is a process that is based on technology that examines data and offers actionable information to help both managerial and executive members as well as end users make more informed business decisions. BI involves various tools, applications and procedures that allow organizations to gather information from internal systems and external sources, prepare it for analysis, develop and run queries against the information, and generate reports, dashboards and data visualizations to provide the corporate decision makers as well as operational workers with the analytical results. The benefits of BI is not limited to accelerating and developing decision making, boosting internal business processes, but also expanding the efficiency of operations, bringing new revenues as well as having remarkable advantages over business competitions. Moreover, BI systems enable organizations to learn about market trends, identify and address business problems. Originally, BI tools were only used by data analysts and IT professionals to perform analyses and make reports with query results for the business users. Nevertheless, gradually, BI tools were used by business executives and workers to discover results and re-define the data inputs.

Moreover, BI technology comprises data visualization tools that can create charts and graphical data presentations, as well as tools that can build BI dashboards and performance scorecards to show business metrics and key performance 
indicators data in an easy visual way, and thus, enable decision makers and strategic management quickly understand how the performance of the organization's processes and operations going through these visual outputs. [22]

Over the past decade, Balanced Scorecard (BSC) has been increasingly implemented by more companies as a key framework to manage their businesses. On top of being an effective communication tool of key strategies, the BSC provides clear connections between strategies, the business processes executed by strategies, and the Key Performance Indicators (KPIs) that measure the business performance. [1]

From a performance management perspective, BSC provides the baseline for performance measurement, and based on industry research, many companies that use the BSC are satisfied with the method and plan to keep on using it. Therefore, it cannot be denied that it is valuable to be able to measure performance from financial, customer, operational, and learning perspectives. [1]

\section{RELATION BETWEEN BI AND BSC}

"The Balanced Scorecard is a performance management tool. It began as a concept for measuring whether the smaller-scale operational activities of a company are aligned with its largerscale objectives in terms of vision and strategy. Organizations were encouraged to measure, in addition to financial outputs, those factors which influenced the financial outputs. The underlying rationale is that organizations cannot directly influence financial outcomes, as these are 'lag 'measures, and that the use of financial measures alone to inform the strategic control of the firm is unwise. Organizations should instead also measure those areas where direct management intervention is possible. In so doing, the early versions of the Balanced Scorecard helped organizations achieve a degree of "balance" in selection of performance measures. In practice, early Scorecards achieved this balance by encouraging managers to select measures from three additional categories or perspectives: 'Customer,' 'Internal Business Processes 'and 'Learning and Growth.'” -Norton and Kaplan

To comprehend Business Intelligence, one must first understand the concept of BSC as a performance management approach. Since BI is a strategy and managing performance examining tool, and BSC is a performance management tool, together they are inseparable. Not only does Performance management allows its users to create forecasts based on what "BI tools" show, but it also collects the data from BI and then helps organizations create an improved plan for the operation or process, and eventually generates the required results.

\section{ADAPTING BI TECHNIQUES AND BSC MODELING: A CLOSER LOOK}

"How can the results of a business strategy framework be presented, evaluated and interpreted?"

This section provides a deeper and detailed discussion of the performance measurement as an adopted BI technique and BSC modeling, as well as the establishment of a measurement framework and the interpretation of the results. A more focus will be brought on inter-relating the BSC and Business Intelligence terminologies and main focus areas from the different reference disciplines. The main target here is to concentrate on how to efficiently display the measurements results by combining the $\mathrm{BSC}$ as a strategic performance measurement tool with BI. Therefore business intelligence techniques and approaches used in the performance measurement and are clearly related to the BSC model especially that $\mathrm{BI}$ is mainly focusing on interpreting big data to results, and this is represented in adopting specific tools or approaches in the business intelligence as shown in figure 1; top BI tools that can be adapted to perform big data analysis and representation to support the decision making, hence in this paper the main tools being under focus are business performance management, spreadsheets and digital dashboards.

On the other hand, BSC as an applied framework for the performance measurement which is -in turn- an applied tool for the business intelligence can be adopted as a strategic and measurement framework, for BSC can be considered as a measurement framework that allows an organization to transform its vision and strategy into a tangible set of performance measures. Moreover, it can be seen as a strategic alignment framework that brings an enterprise view of an organization's overall performance via combining financial measures and other key performance indicators around customer perspectives, internal business processes, and organizational growth, learning, and innovation.

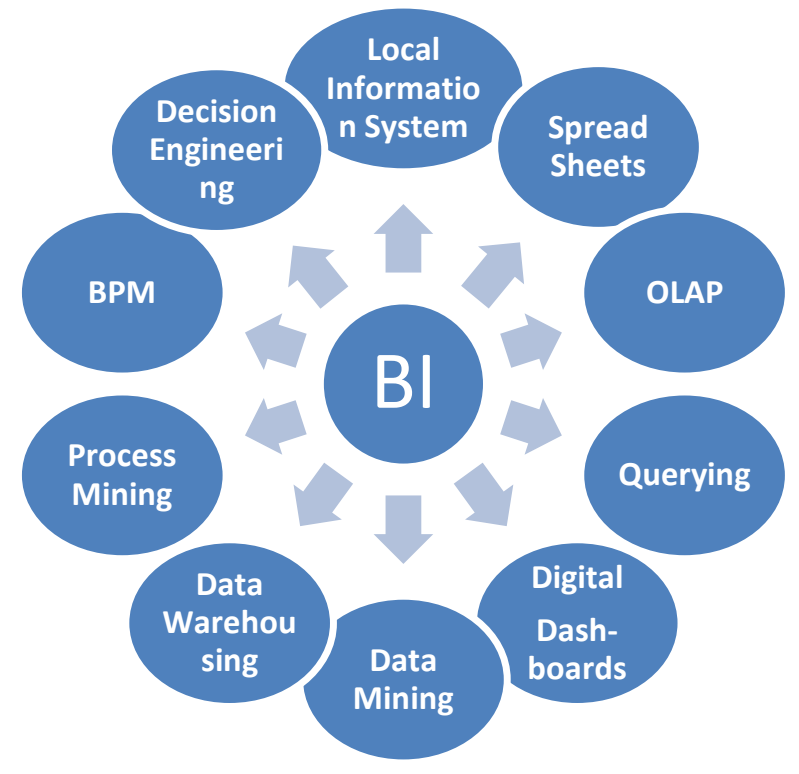

Figure 1 Business Intelligence tools [20] 
Figure 2 displays the perspectives along with the BSC framework elements, including aligning the strategy to the BSC perspectives and in turn connecting the perspectives to their objectives, measures, targets and management initiatives.

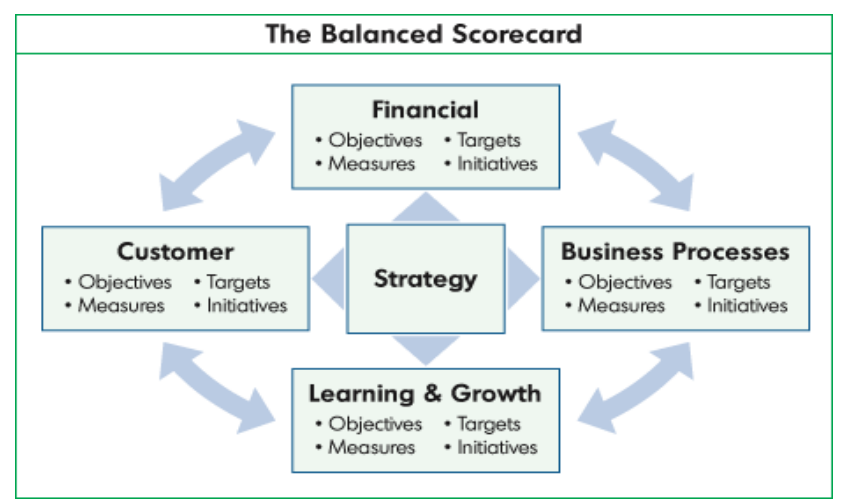

Figure 2 BSC elements

\section{BI APROACHES AND TOOLS}

For the term intelligent, BI can be seen from two perspectives. The first is translating the human intelligence capacity applied in business activities and using artificial intelligence tools to solve the different business problems.

The second perspective is seeing the intelligence as information centric that decodes data, knowledge and technologies used to efficiently manage the organizations' businesses and help aligning the business to the performance measurement. [15]. Currently, BI is crucial because it carries out constant analyses of numerous data and considers different variants of organization performance. [11]

For the most effective results of applying BI in an organization, it is recommended to follow certain approaches. BI basic 3 approaches as referenced by [12] are:

1- Decipher what happened

2- Impact the here and now

3- Create a new future

As figure 3 displays the 3 approaches, in the first approach, this BI type focuses on outlining the history of the organization in order to create a foundation for decision making. The approach extracts data, integrate and standardize it, the use the information-reporting technologies to review and summarize the data.

The second approach relates to how to achieve targets, and how the ad-hoc alerts for the performance measurements take ongoing actions and decisions. Hence, it is important to offer guidance for the real time decision makers, and this is achieved only through developing business processes maps and building performance metrics.

The third approach uses a future perspective. This perspective uses historical information along with quantitative methodologies to support forecasting through visual models.

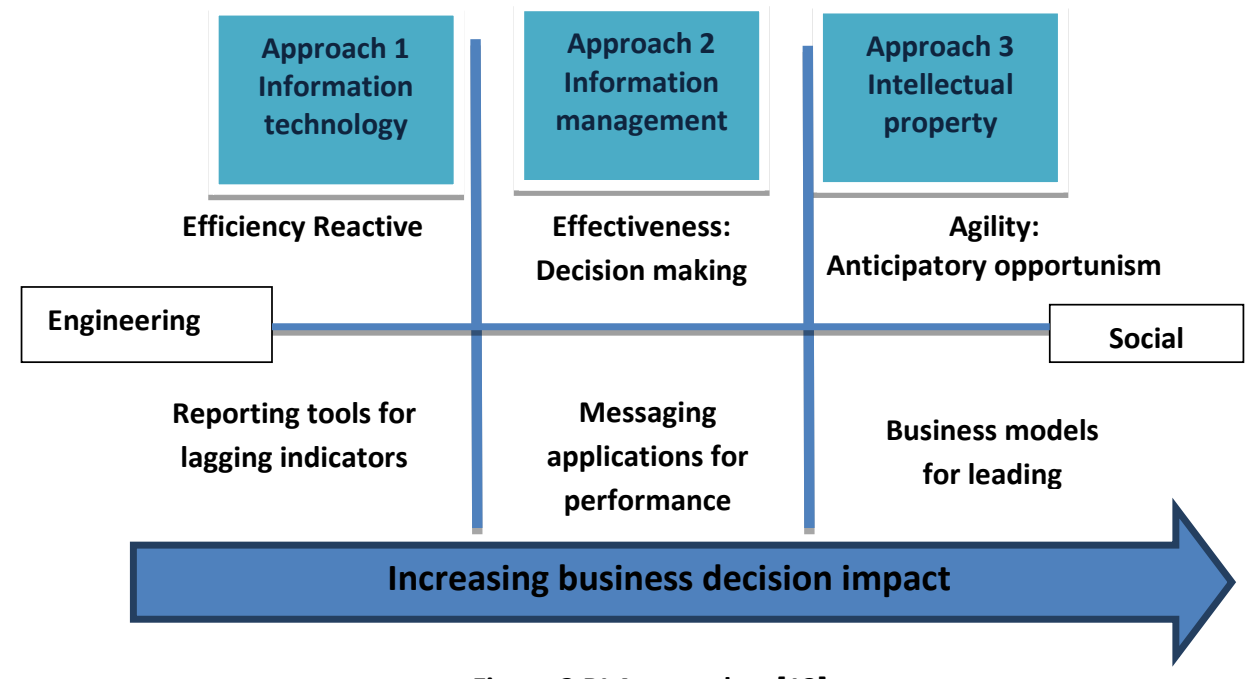

Figure 3 BI Approaches [12]

BI tools are software types intended to retrieve, analyze and report data. This broad definition -has various forms such as spreadsheets, visual analytics, and querying software to data mining, warehousing, and decision engineering. What BI mainly does is to deliver required business information in a usable form to decision makers.

In the BI field, there are many tools that can be used, as this field becomes very important for top management and decision makers in order to have better performance management measures. This paper concentrates mainly on BI tools that utilize visual presentation of the data and reported measures, for this approach makes interpreting data easier in a timely matter, and accordingly, take corrective actions based on the reported graphs to enhance the profit and efficiency.

The BI visualization tools are presented in table 1 . For the sake of the analysis, this paper examines BI from three different dimensions. They are:

a) Making better decisions in a timely manner,

b) Transforming available data into more useful information 
c) Empowering the management with better tools to make rational decisions.

\section{a) Making better decisions in a timely manner} BI mainly helps people make decisions to improve performance and create a unique competitive advantage in the market. It empowers organizations to make better decisions in a timely manner [21]. All types of managers make decisions according to their experiences, their understandings, business plans and available information. Generally, experiences and understanding change very slowly. Nevertheless, information changes rapidly, which makes it a bit difficult to grasp and understand their significance. Making better decisions means making changes in the process that would result in more accurate decisions, and eventually, better achievement of corporate objectives.

\section{b) Transforming available data into more useful information}

Making better decisions in a timely manner requires having the right and relevant information delivered to the managers and decision makers. While this is a fact, yet organizations always face "analysis gap" [21], which means the gap between the required information by decision makers and the already collected large amount of data.

To avoid this "analysis gap", organizations tend to develop BI systems that would transform raw data into valuable information. The mission of an effective BI system is to instantly provide the decision makers with the required information after filtering and analyzing the tons of available data, which is known as "analysis at the speed of thought". The main issue here to focuses on is for BI to be able to answer a question at the second it is formulated, creating a quantum leap in the analysis quality, which eventually leads to a better business understanding. [Few, 2005]

It is a dim view that some people consider the baseline description of BI is to just deliver useful information, as applications and systems collect the massive amount of data transforming them into useful information to help manage business activities within the organization. [21]

Defining which piece of information is useful and relevant to a decision is considered the most difficult part of BI. At the enterprise level, BI solutions are charged with the collecting the important metrics for this organization, which is known as key performance indicators (KPIs).

\section{c) Empowering the management with better tools to make rational decisions}

Defining BI as a rational approach and a management philosophy, organizations tend to use BI due to the belief that the right way to make a decision is rational approach. [Vitt and Luckevich, 2002]

The characteristics of BI attitude are as follows:

- Searching for the objective measurable business facts (data).

- Analyzing data via systematic technologies.

- Creating prototypes that explain the cause and effect relationships between actions, and their effect on achieving business goals.
- Testing different approaches and observing results feedback.

- Realizing that people are irrational sometimes

- Making the decisions and performing actions based on the above characteristics.

To conclude, the adopted tools for the BI - as well as in this paper - are the set processes to manage an organization's performance. They include spreadsheets, digital dashboards and business performance management.

Table 1 Current BI Techniques [15]

\begin{tabular}{|c|c|}
\hline TECHNIQUE & DESCRIPTION \\
\hline Predictive modeling & $\begin{array}{l}\text { Predicts value for a specific data item } \\
\text { attribute }\end{array}$ \\
\hline $\begin{array}{c}\text { Characterization } \\
\text { and descriptive data } \\
\text { mining }\end{array}$ & $\begin{array}{c}\text { Data sharing, dispersion and } \\
\text { exception }\end{array}$ \\
\hline $\begin{array}{l}\text { Association, } \\
\text { correlation, } \\
\text { causality analysis } \\
\text { (Link Analysis) }\end{array}$ & $\begin{array}{c}\text { Categorizes relationships among } \\
\text { attributes }\end{array}$ \\
\hline Classification & $\begin{array}{l}\text { Determines which data item belongs } \\
\text { to which class }\end{array}$ \\
\hline $\begin{array}{c}\text { Clustering and } \\
\text { outlier analysis } \\
\text { Partition }\end{array}$ & $\begin{array}{l}\text { Divides a set into classes, whereby } \\
\text { items with similar characteristics are } \\
\text { grouped together }\end{array}$ \\
\hline $\begin{array}{c}\text { Temporal and } \\
\text { sequential patterns } \\
\text { analysis }\end{array}$ & $\begin{array}{l}\text { Trend and deviation, sequential } \\
\text { patterns, periodicity }\end{array}$ \\
\hline $\begin{array}{l}\text { OLAP (Online } \\
\text { Analytical } \\
\text { Processing) }\end{array}$ & $\begin{array}{l}\text { OLAP tools enable users to analyze } \\
\text { different dimensions of } \\
\text { multidimensional data. For example, } \\
\text { it provides time series and trend } \\
\text { analysis views. }\end{array}$ \\
\hline Model Visualization & $\begin{array}{l}\text { Makes discovered knowledge easily } \\
\text { understood via charts, plots, } \\
\text { histograms, and other visual means. }\end{array}$ \\
\hline $\begin{array}{l}\text { Exploratory Data } \\
\text { Analysis (EDA) }\end{array}$ & $\begin{array}{l}\text { Explores a data set without a strong } \\
\text { dependence on assumptions or } \\
\text { models; goal is to identify patterns in } \\
\text { an exploratory manner }\end{array}$ \\
\hline
\end{tabular}

\section{THE ADOPTION OF BSC: A STRATEGIC VIEW}

This section will provide background details on how BSC was used as a measurement framework for enterprises, along with its importance, strength points and the faced challenges.

In 1992, Harvard Business School professor Robert S. Kaplan and management consultant David P. Norton developed the balanced scorecard as a performance measurement tool. Kaplan and Norton found out that in the innovative business world, traditional financial measures cannot draw an organization's performance correct picture. Therefore, instead of making managers choose between "hard" financial measures and "soft" operational measures - for example product development cycle times, or employee satisfactionthey created a method that would use both measures types with balance. "The balanced scorecard includes financial measures that tell the results of actions already taken".

Banker, Chang, Pizzini (2004) explained BSC as "an essential aspect of the BSC is the articulation of linkage between 
performance measures and strategy objectives, once linkage is understood, strategic objectives can be further translated into actionable measures to help organizations improve performance". [17]

The adopted BSC research definition is: BSC is a strategic management and measurement framework that enables the organizations to align their strategic objectives with their performance targets to better evaluate the organizations position in a balanced way to meet both the financial and nonfinancial measurements.

According to Financial Times, the balanced scorecard concept was successful since its introduction, and it was adopted by 80 percent of large U.S. companies as of 2004, leading it to be the most popular management tool that would improve performance. Additionally, since its promotion by the National Partnership for Reinventing Government, it has been greatly applied in the public sector. The reason for the BSC wide spread, is that it is consistent with the companies' many common performance improvement initiatives, such as customer-supplier partnering. BSC helps managers comprehend the complex interrelationships among different business areas. BSC draw attention to situations when relating the elements of an organization's competitive strategy in a single report.

After implementing the BSC successfully, the next task is to collect and analyze the data. Since this is a time-consuming process, as the data is allocated in different computers all over the company, some technological advances - enterprise resource planning systems, decision-support tools, groupware, and data warehouses - made data collection and analysis considerably easy by the 2000s, and even many software vendors produced BSC applications for desktop computers. Typical software packages enable users to plug in the selected performance measures to be monitored. The computer then collects the data and provides performance grades according to formulas created by the company. Thus, electronic balanced scorecard applications automated the process of performance measurement.

Using computer technology by Kaplan and Norton provided information and support to organizations adopting the BSC. For example, Norton's consulting firm, Renaissance Worldwide Inc., and Gentia Software formed the Balanced Scorecard Technology Council. This virtual users group sponsors a Web site (www.balancedscorecard.com) that provides research, product information, and a forum for ideas. Moreover, Kaplan and Norton founded an organization named the Balanced Scorecard Collaborative "to facilitate worldwide awareness, use, enhancement, and integrity of the Balanced Scorecard as a value-added management process. [19]

\section{A. BSC Evolution}

The BSC has evolved in three generations. The first BSC generation was a performance measurement system that did not stress the cause \& effect relations among strategic objectives, while the second generation highlighted these relations using strategy maps to emphasize the relations between strategies and measures, The third BSC generation emphasized using 'activity' and 'outcome' perspective to develop strategic control system .[18]

According to Arab British Academy for Higher Education, the balanced scorecard, the word "scorecard" indicates quantified performance measures, and the word "balanced" denotes that the system is balanced among:

- Short-term and long-term objectives

- Financial and non-financial measures

- Lagging and leading indicators

- Internal and external performance perspectives

Hence, Balanced Scorecard is:

1-To efficiently transform strategic goals into perceptible objectives and measures, [16]

2- A strategic management system used to identify strategy and to translate it into action [5]

\section{$B$. BSC Framework Strengths}

The aim of using BSC is to achieve balance rather than concentrating on a certain performance section. Using BSC framework enables managers to see the full business perspectives as opposed to the financial perspective only. The BSC main strengths are that it is scalable and used in different operation levels, for BSC reviews the organization's customers, employees, internal processes as well as growth and potential strengths. It also helps managers make proactive decisions. A good BSC helps visualizing how an organization should handle its processes and get results. To sum up, BSC can be seen as:

- A multi focused framework

- A goals achievement measurement tool

- A motivation and rewarding system

- An intellectual capital performance tool

- A benchmarking tool

- A linkage tool between the business processes, objectives and strategic perspectives and objective

\section{BSC Framework challenges}

Although organizations seek using BSC due to its simplicity, Professor Claude Lewy of the Free University of Amsterdam found that $70 \%$ of its application fails. This was due to its time consumption and high cost. Although Professor Lewy states the efficiency of BSC in organizations, he stresses on that organizations should have a very clear vision on what they want to accomplish, and are ready to devote the required resources to implement the BSC correctly. Thus, before implementing a measurement system, it is crucial to have a clear definition of the organization's strategic goals and objectives, and relate them to the organization's mission and vision. [14]

It is suggested that an organization would use a pilot version instead before moving on to a full-scale implementation. Testing the BSC in a few business areas allows managers to make necessary changes and increase support for the initiative before moving on to all organization's departments. [14] 


\section{$D$. BSC success factors}

Factors that lead the BSC to succeed are:

1. Adapting a Consistent Process while Building the BSC Framework

In order to establish a good performance measurement system, a consistent process definition for the measurement model during creating the performance framework. The main phases that a successful Scorecard goes through are: Design, development, implementation, and sustain (or institutionalize) its use. Consequently, the "top ten success factors" list for a successful BSC model is as follows:

- Gain top leadership support to help if there is a 'burning platform'.

- Measure the right things, in which customers, stakeholders, and employees find value, and not everything.

- Create a governance process involving all key stakeholders.

- Design the system to follow the actual work of the organization.

- Start development of measures at both the top and bottom of the organization and cascade them in both directions.

- Make a communications campaign to describe the reflection of Scorecard on missions.

- Arrange systems in line with the organization's planning, measurement, and budget cycles.

- Ensure the process credibility and honesty in reporting.

- Create a real-time information transparency, which provides credibility and usefulness to managers.

- Relate incentives based on effective evaluation and performance appraisals. [7]

Design. The biggest challenge in creating a successful BSC lies in engaging all organization staff along with customers and stakeholders in the design phase. It mainly depends on the "top leadership" support, which can be defined as staff, program, or a "parent" organization. With this type of support in hand, the main factor is not to measure everything, but to measure the right things in which customers, stakeholders, and employees find value.

Making a communications campaign to describe the reflection of Scorecard on missions is crucial to gain support for collecting and reporting new measures. Members of an organization must understand the value of information in their discussions, and they should be trained on using their main performance metrics in order to improve their performance.

Implement. If the regularly used administrative systems like budget development and implementation cycles - are not linked with developing and reporting Scorecard measures, then it will not be of use.

Among the main success factors is the process credibility and reporting. Regular meetings between the BSC building team are required to review collected data and reports. This is to create a real-time information transparency.
Sustain. Sustaining Scorecards over time is one of their biggest challenges faced. To ensure that data credibility continues, the organization must create a real-time information transparency, which provides credibility and usefulness to managers. Adding to this factor, there is also the factor of relating incentives based on effective evaluation and performance appraisals.

On top of those factors, there are recommendations to have lessons learned easily through teaming up with an organization that has already been through this process.

Seeing it as a learning tool, the Scorecard approach provides discipline and a common language within an organization to become a performance oriented, fact-based, and customercentric organization. Conclusively, for the frequent Scorecard users, Scorecard can be seen as a different communication method rather than just a measurement approach. [7]

2. Choosing the right Key Performance Indicators Since many organizations select indicators that monitor the cash flow and business cost, they consider 3 main areas when selecting KPIs to verify if there are any issues in the cash flow or profitability as they show instantly in the numbers. They areas are costs, working capital and sales. Such indicators help the organization reach its goals.

BSC consultants should ensure that selected KPIs can be tracked at all times, because this helps managers identify any potential problems or opportunities by looking at the history of a KPI. Another important factor for the success of BSC is reviewing the indicators and having managers to directly approve/reject them, for this enables them to change indicators to better ones.

\section{BSC IMPLEMENTATION}

How to develop and execute a balanced scorecard?

In order to build a consistent balanced scorecard framework, the below illustrated steps are followed: [7]

1. Transform the organization's strategic plan into goals fitting under the four perspectives.

The organization's strategic plan should be reviewed to clarify its direction for the next 3-5 years. Once the plan is reviewed and confirmed, the organization can use it decide which goals are required under which perspective.

Among the questions that can help an organization decide its goals are: What does it mean to achieve financial success based on the strategic plan? What are the main sources of financing for the Customer perspective? For the internal processes perspective, what can be done to serve clients efficiently? What ensures that the organization is properly meeting the clients' demands? For the learning and growth perspective, what does the organization do to ensure that its employees are well and efficiently trained?

An organization should be in accordance with the stakeholders in order to complete the transforming process. It should collect feedback from all organization departments as well as clients to implement its processes smoothly without any surprises coming in the way. 
2. Develop easily tracked measures to confirm the organization is meeting its goals.

For smaller organizations, scorecards can be simple and short, with one measurement for each perspective. Once the staff becomes familiar with the tool, more measurements can be added then. For medium-sized organizations, the measures can be up to four as a start.

Kaplan and Norton define effective measures as clear, available on a timely basis, valid - that they represent exactly what should be measured - and their profits exceed their cost.

An example here is a small shop with the goal to raise its donor base, the best measure here would be tracking "entire raised amount, the percentage received from a first time donors".

\section{Linking the scorecard to departments and individuals.}

This step applies more to medium to large -sized organizations. Norton and Kaplan state that after the organization develops the BSC, they need to link measures to the performance of departments and staff, so that to have ownership for these measures. For example, program managers can own internal processes measures while fundraisers can own the financial related measures.

It is recommended for measures to be quarter-based or semiannually, in order to reach an agreement of when to use the scorecard to measure the departments and individuals performance.

4. Set targets, create an action plan and allocate resources. After making the measures ownership, according to Kaplan and Norton, both departments and individuals will be developing the required targets to be achieved within the agreed measurement date. The next step is to create an action plan to achieve these targets. Finally, the proper budget and the right resources are allocated to implement the action plan.

For example, the small shop with the goal to raise its donor base, the target should be Achieve $30 \%$ of entire raised amount should be from first time donors within six months. Asking for donations from small business in this organization's neighborhood could be among the items of its action plan.

\section{Review, learn, and revise.}

Upon the agreed measurement date, it is recommended to review the action plans to check if targets were met, not met or exceeded. If they have not been met, check what could have been done to realize them and another review of the strategic plan and scorecard should take place. It could be more staff needed or extra budget to be allocated, etc. Such procedure determines if there is collaboration among perspectives, and if best practices are being shared among the organization's departments. It is recommended that scorecards be reviewed annually, yet, whenever the strategic plan is reviewed, the scorecard should be reviewed as well to reflect those modifications.

In summary; it is obvious that what you measure is what you get. [6]
Defining an organization mission and vision is the first step to build a BSC framework. Then comes the alignment with the organization's goals and strategies.

\section{Designing a BSC is accomplished in four steps: [6]}

1) Translating the vision into operational goals;

2) Communicating and linking the vision to individual performance;

3) Business planning and index setting

4) Feedback and adjusting the strategy correspondingly. Initially, BSC was created as a performance measurement tool including financial and non-financial measures. After confirming that the organization's vision and strategy are related to its objectives and measures, the result would be transforming the BSC from just a performance management tool to a strategic tool. [6]

In the Strategy-Focused organization, they show how the following five principles transform the Balanced Scorecard from a tool for performance measurement to a tool for creating a strategy-driven performance management company:

1) Translate the strategy into operational terms. Use the Balanced Scorecard to describe and communicate strategy in consistent, insightful, and operational terms.

2) Align the organization to the strategy. For organizational strategies to work, they should be linked and integrated across many functions - finance, manufacturing, sales, marketing and so forth. The Balanced Scorecard can link these contrasting and detached functions.

3) Make strategy everyone's everyday job. Use the Balanced Scorecard to educate the organization about strategy, help employees develop personal objectives, and then compensate them based on their adherence to and implementation of the business' strategies.

4) Make strategy a continual process. Use the Balanced Scorecard to link strategy to the budget process, review strategy regularly in management meetings, and develop a process for learning and adapting strategy.

5) Mobilize change through executive leadership. Through a method of mobilization, governance, and strategic management, executives can embed new strategy and new culture into their management systems, creating continual process to meet the strategic needs of today and tomorrow.

\section{BSC BUILDING STEPS}

The first step towards building a successful BSC framework is to define the organization vision, then the strategy for achieving this vision should be stated clearly, then the measuring of achieving the strategic elements and the success of the organization goal is then defined,

After defining the vision and the strategy, the four main perspectives that are necessary in the BSC building are attached to the organization objectives; the four main perspectives of a balances scorecard are:

\section{1- The financial perspective}

The financial perspective addresses the question of how shareholders view the firm and which financial goals are desired from the shareholder's perspective. These goals depend on the company's stage in the business life cycle. 
For example:

- Growth stage $\rightarrow$ goal is growth, such as revenue growth rate

- $\quad$ Sustain stage $\rightarrow$ goal is profitability

- Harvest stage $\rightarrow$ goal is cash flow and reduction in capital requirements

\section{2- The Customer perspective}

The customer perspective addresses the question of how the firm is viewed by its customers and how well the firm is serving its targeted customers in order to meet the financial objectives. Generally, customers view the firm in terms of time, quality, performance, and cost.

\section{3- The internal perspective}

This perspective addresses the internal processes in an organization, what are the critical processes, what are the objectives and targets needed to be defined from the customer as well as the shareholders point of view; for example the manufacturing excellence and the development productivity.

\section{4- The learning and growth perspective}

This perspective addresses the view of the learning, innovation and the improvement trend that should be focused by the organization in order to meet its objectives.

\section{What and how to measure?}

Within each of the Balanced Scorecard financial, customer, internal process, and learning Perspectives, what to measure and how to measure objects should be defined. What to measure is represented in the definition of the strategic objectives under each perspective, therefore how to measure is represented in the key performance indicators -measuresthat are built to measure the achievement progress of the objectives targets. Each KPI is represented by a set of properties or values that are essential to configure the performance measurements results these properties are:

- Base Value (the value which is considered the current value for the objective achievement in a firm)

- Benchmarking Value the value for the measure in the benchmarking organizations

- $\quad$ Target Value the target value for the measure lying under an objective

Then the management initiatives that will address the potential set of actions that are required to achieve the targets should be addressed. [9]

\section{BI AND BSC RELATION}

"If companies align balanced scorecards and business intelligence they can achieve a performance management system that delivers superior results. "[1]

Over the past decade, business performance management (BPM) frame works such as the Balanced Scorecard have been adopted by a growing number of major organizations. A 1999 Bain \& Company survey of adoption of management tools revealed that almost $44 \%$ of firms in the survey used the Balanced Scorecard, and that the mean satisfaction rating among users was 3.85 , with 5 being the highest rating. While a number of other management tools had higher adoption rates and higher satisfaction rates, the data suggest that BPM frameworks such as the Balanced Scorecard will be a staple within large organizations for the foreseeable future, more and more companies are using the Balanced Scorecard as a management tool to improve business results. [1] Strategic Performance Measurement means to make a business successful as the budget process. Just as with setting nearterm direction for the company with a budget, management has the responsibility for setting longer-term strategic direction and goals for the company. Examples of strategic management activities are deciding what markets the company will target, and determining what does the company need to compete in these markets. What specific products or services will be offered for customers, and why? How will a competitive advantage be achieved and sustained with these products and services? How employees are best trained to be most effective in handling the needs of customers? What internal processes that most critically need improvement to reduce cost or increase level of service? Simply put, Strategic Performance Measurement lets the company focus on those goals and activities that will make a difference 2,3 , or even 5 years down the road. The lead-lag relationship between strategic activities undertaken in the present is enormous, so the decisions made for direction set is critical for the longterm success of the company.

Even more important is ensuring the strategic success drivers are being achieved. This is why all employees should be concerned, aware, and knowledgeable of how their day-to-day jobs are involved with these strategic activities. Strategic Performance Measurement is a formal way of focusing not only managers but also for each employee in the company in each department or function on these critical activities [8].

Presenting the measurements results is the most important part after having all strategic objectives, key performance indicators and initiatives defined, and connecting them with the target values upon which the measure will be measured.

Using the business intelligence techniques in defining the BSC parts and representing the BSCs results will have a positive effect in understanding as well as analyzing the business parts and the measurement results, which leads to having the necessary actions defined.

Presenting the balanced scorecard structure in the most simple, readable and neat way is very important to provide the correct directions for the business strategies. So, business intelligence can be used to present the BSC structure in addition to presenting the output values using charts, dashboards, strategy maps (to represent the cascading relations among the objectives in different perspectives), trending graphs and figures. The output data can be stored in knowledge bases, and data mining techniques can be used for the future analysis and trends. Different delivery channels can present the BSC data (the linkage between the perspectives, objectives, KPIs, management initiatives and actions such as Excel formatted kpis, Mobile applications, Desktop applications and Web based solutions. When approached as a means to support corporate strategy, business intelligence (BI), solutions can enhance performance management programs' ability to optimize value to the organization.

Companies become handicapped by limited low-quality data views when they allow the already available information, which is easiest to gather, determine how they manage the business. It makes sense that an organization should first make decisions about its strategies and information requirements, then subsequently align information assets to support strategy management. But many companies continue to operate in reverse. [4] 
The business intelligence balance scorecard is designed in such a way that the results are easy to understand and interpret. The scorecard is unique in its structure because it will assess how a company's business intelligence system and data warehousing compares with the best in the industry. It helps you establish IT standards, identifies what kind of data you need to gather, and evaluates the history of business intelligence within your company.

A business that is pursuing Balanced Scorecard strategic alignment can use BI solutions for trend analysis, predictive analysis, customer data integration, scorecards and dashboards, and data mining. it has been found through studies that the most successful organizations proven performance management methodologies are depending on
Business intelligence will contribute in providing trend analysis, predictive analytics, integrated customer views, scorecards and dashboards, thus, the representation of the strategic performance results will be more readable, and can help the decision makers in taking more consistent trends in getting their targets done. Table 2: illustrates a comparison between the BSC and BI as management tools

how to present the measure and follow up them using tools such as strategy maps and Balanced Scorecards, then choose metrics based on the strategic objectives set through those methodologies, and finally deploy business intelligence solutions to gather the data necessary for performance optimization.

Table 2 Comparison of Balanced Scorecard and Business Intelligence as Management Tools. [1]

\begin{tabular}{|c|c|c|}
\hline $\begin{array}{l}\text { Points } \\
\text { Comparison }\end{array}$ & Balanced Scorecard & Business Intelligence (BI) \\
\hline $\begin{array}{l}\text { Vintage and } \\
\text { Central Objectives }\end{array}$ & $\begin{array}{l}\text { Circa 1996. Communicate business strategies and align } \\
\text { organization. Manage strategy execution. Measure } \\
\text { organizational performance. Align goals, compensation, } \\
\text { skills, resources, budgets, and plans. }\end{array}$ & $\begin{array}{l}\text { Circa 1994. Leverage business } \\
\text { information, analytical tools, and } \\
\text { decision support techniques to } \\
\text { improve core business processes that } \\
\text { improve business performance and } \\
\text { profits. }\end{array}$ \\
\hline $\begin{array}{l}\text { Organizational } \\
\text { Scope }\end{array}$ & $\begin{array}{l}\text { Mainly enterprise, with cascading performance measures to } \\
\text { SBUs, divisions, departments, and so forth. } \\
\text { Can be applied at SBU and lower levels independently of } \\
\text { whether or not there is a higher-level. }\end{array}$ & $\begin{array}{l}\text { Enterprise, SBU, division, function, } \\
\text { departments, and so forth. Can be } \\
\text { applied, and often is, at any of these } \\
\text { organizational levels independently, } \\
\text { though that may not be ideal. }\end{array}$ \\
\hline Customer Focus & $\begin{array}{l}\text { Mainly internal for all levels of executives, managers, and } \\
\text { analysts. }\end{array}$ & $\begin{array}{l}\text { Mainly internal for all levels of } \\
\text { executives, managers, and analysts. } \\
\text { Can also be used to augment product } \\
\text { and/or service offerings to external } \\
\text { customers. }\end{array}$ \\
\hline $\begin{array}{l}\text { Key Management } \\
\text { Linkages }\end{array}$ & $\begin{array}{l}\text { Links business strategies to key business processes and } \\
\text { initiatives that drive strategy execution and business } \\
\text { performance. Links strategies to goals, compensation, skill } \\
\text { development, resources, budgets, and plans. }\end{array}$ & $\begin{array}{l}\text { Links business strategies, core } \\
\text { business processes and initiatives, and } \\
\text { business information, analytical tools, } \\
\text { and decision support techniques that } \\
\text { can be used to improve those core } \\
\text { business processes and achieve } \\
\text { strategic goals. }\end{array}$ \\
\hline $\begin{array}{l}\text { Information Strategy } \\
\text { and Focus }\end{array}$ & $\begin{array}{l}\text { Primarily ad hoc, manual reporting } \\
\text { of performance measures from } \\
\text { financial, customer, operational, and } \\
\text { learning perspectives. Some multi- } \\
\text { dimensional analysis using BI tools, } \\
\text { often using stove-piped approach to } \\
\text { data acquisition }\end{array}$ & $\begin{array}{l}\text { Integrate multi-dimensional business } \\
\text { information to support use of wide } \\
\text { range of automated analytical tools } \\
\text { and decision support techniques to } \\
\text { improve the efficiency and } \\
\text { effectiveness of core business } \\
\text { processes that drive business results. }\end{array}$ \\
\hline $\begin{array}{l}\text { Performance } \\
\text { Management Focus }\end{array}$ & $\begin{array}{l}\text { Measure performance of strategically important business } \\
\text { processes and take action to improve as needed. Use } \\
\text { performance measures to guide strategic investments and } \\
\text { plans. }\end{array}$ & $\begin{array}{l}\text { Use well-managed enterprise business } \\
\text { information, automated analytical } \\
\text { tools, and modern decision support } \\
\text { techniques } \\
\text { to manage and improve core business } \\
\text { processes that determine overall } \\
\text { business performance and profitability }\end{array}$ \\
\hline
\end{tabular}


From table 2 it is obvious that there are some sort of common focus points between the BSC and the BI, meanwhile the BSC is essential to measure and to present the strategy while the $\mathrm{BI}$ is essential in interpreting the measurement results.

The "Business Intelligence" (BI) generally refers generating data-driven insights on business performance. Balanced Scorecard deals with business performance as well. Although these two business methods work in the same field, there is not much information about integration Balanced Scorecard in $\mathrm{BI}$ or about the integration of BI into the Balanced Scorecard. $\mathrm{BI}$ is usually represented by set of process steps, BI process can be represented as:

1. Obtaining data or information.

2. Using analytical tools to process the data

3. Making decisions according to data insights.

\section{BSC ROLE IN BI}

While the possibilities of data collection seem to be unlimited and growing each day, we should be focused on what matters. Here is where BSC helps. Any effort to collect data and analyze it to obtain information should be aligned to the strategic objectives of the company represented in the strategy map of the BSC. In this way companies will focus on what matters only. BSC gives an idea about what kind of insights should be searched for by using BI analytic tools.

Clearly there is an evolving need to have the dashboards based data reporting as a way for well defining and presenting the data deciphering results, the performance measurement layer is providing executives, management, analysts to effectively view and use information to make decisions. Dashboards and scorecards are analytic and presentation technologies where performance measurement presentation is perceived.

\section{CONVERTING INSIGHTS INTO KPIS}

Next collected data should be properly converted into a data source for the KPIs of the Balanced Scorecard. As a result, data insights of BI might be used for action plans aligned to KPIs of the BSC. Normally BI is what helps to generate actionable KPIs.

\section{E. Integration between classical BI and classical BSC}

In summary; BSC and BI interconnection can be summarized in the following

- BSC focuses BI data collection and analytic on what matters by providing strategic objectives.

- BI feeds KPIs of Balanced Scorecard with insightful data.

- BI can be a source for action plans aligned with strategic goals and KPIs.

- $\quad$ BSC-BI integration is recommended when there is a base for a strong business-centric BI architecture.

- $\quad$ BSC is used in the BI architectures as a valuable adon to explore more business opportunities as BSC focuses on getting the data that matters and classify it in a relational way.
In order to use the BI in an efficient presentation and consolidation of the performance measurement; major steps are followed such as:

- Data Collection

- Entity close definition which includes defining and mapping the entity's objectives that are completely derived from the entity strategy

- Data consolidation (Internal and external reporting

\section{SUMMARY}

This paper highlighted the relation between the balanced scorecard and BI tools, and how to maximize the overall organizational performance using the BSC and BI tools. BSC enables the performance measurement to take place and $\mathrm{BI}$ enables managers to review the performance results and to take the proper management initiatives; therefore when choosing performance indicators, BSC consultants should ensure that they can be compared in the past, present and future. This is an essential consideration as plotting the values for the measure over a time period that encompasses the history of the measures values, and the current values will help the mangers to identify the potential problems as well as the opportunities. Reviewing the selected indicators and having the direct managers' approvals on them is also an important factor in having the BSC measures take place, accordingly extra KPI can be removed or exchanged with a better indicator set.

A business that adapt Balanced Scorecard as a strategic performance measurement framework can use BI solutions for trend analysis, predictive analysis, customer data integration, and performance reporting dashboards. It has been found that the most successful organizations adopt performance management methodologies such as Strategy Maps and the Balanced Scorecard, and then choose metrics based on the strategic objectives set through those methodologies, and finally deploy business intelligence solutions to gather the data necessary for moving the business forward and achieve the long term goals and vision.

\section{REFERENCES}

[1] Williams, "BI and Balanced Scorecards: Key Tools in the Performance Management Toolkit," Decision Path Consulting, 2008.

[2] M. Nemtsev, "Balanced Scorecards and performance point," senior consultant, Gen-I, 2010.

[3] S. Ghosh, S Mukherjee "Measurement of corporate performance through Balanced Scorecard : an overview," Vidyasagar University, Journal of Commerce, Vol. 11, 2006.

[4] Paladino and Williams "Moving strategy forward: merging the Balanced Scorecard and Business Intelligence," Business Performance Management, 2008

[5] Robert S. Kaplan, David P. Norton, "The strategy focused organization," Vol. 23, No. 1(3 parts) Part 1, 2001.

[6] Robert S. Kaplan, David P. Norton, "The Balanced Scorecard - measure the drive performance," Harvard business review, 1992.

[7] John M. Kamensky, "Top ten list: key factors that make a Balanced Scorecard successful,'IBM center for the business of government, 2005. 
[8] B Kali, "Strategic performance measurement," RK Business Development LLC, 2003.

[9] Arab British Academy for Higher Education, "The Balanced Scorecard", 2012.

[10] Paul R. Niven R 1,"Balanced Scorecard step-by-step: maximizing performance and maintaining results," ISBN-10: 0471780499, ISBN-13: 978-0471780496, Edition: 2, 2006.

[11] Olszak and Ziemba, "Approach to Building and Implementing Business Intelligence Systems," Interdisciplinary Journal of Information, knowledge, and Management, Volume 2, 2007

[12] IBM Gartner, "A step-by-step approach to successful Business Intelligence", featuring research from Gartner, 2011.

[13] Wolk and others, "Building a performance measurement system- using data to accelerate social impact", Root cause Cambrige, 2009.

[14] Lewy, Claude, and Lex Du Mee. "The Ten Commandments of Balanced Scorecard Implementation." Management Control and Accounting, April 1998
[15] Ranjan.J , "Business intelligence: concepts, components, Techniques and benefits", Journal of Theoretical and Applied Information Technology, 2009

[16] Braam and Nijssen, Performance effects of using the Balanced Scorecard: a note on the Dutch experience, Long Range Planning 37(4), 335-349 (2004)

[17] Salem and others, "balanced scorecard: weaknesses, strengths, and its ability as performance management system versus other performance management systems", Journal of Environment and Earth Science www.iiste.org ISSN 2224-3216 (Paper) ISSN 2225-0948 (Online) Vol 2, No.9, 2012

[18] Yadav, "Era of Strategic Performance Management Post 2000: Thinking Beyond Balanced Scorecard (a Literature Review), 2011

[19] Hillstrom, "Encyclopedia of business, 2nd edition", 2014

[20] http://www.predictiveanalyticstoday.com/businessintelligence-solution/

[21] Vitt, E., Luckevich, M. \& Misner, S. (2002). Business intelligence: Making better decisions faster. Washington: Microsoft Press Redmond.

[22] Rouse, October 2014, http://searchdatamanagement.techtarget.com/definition/b usiness-intelligence 